\title{
Pointyng Correction in Phase Equilibrium Thermodynamics of Non Polar Gases and Brines: A Review
}

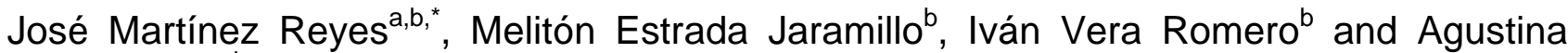 \\ Ortiz Soriano ${ }^{\mathrm{b}}$
}

\author{
${ }^{a}$ National Autonomous University of México, México \\ ${ }^{b}$ University of the Ciénega of Michoacán State, México
}

\begin{abstract}
The development of an equation for Poynting correction, is of paramount importance in the field of modeling and interpretation of phase equilibrium thermodynamics in a wide range of temperatures and pressures /densities for practical applications in chemistry, physical chemistry, geochemistry and industrial technology. The unique previous existing equation for Poynting correction is a simple expression, represented by a product of a constant volume by a pressure difference between wich the correction is applied. [1] proposed an equation based on a semitheoretical expression for the partial molar volume at infinite dilution of volatile aqueous non-electrolyte solute $\left(V_{2}^{0}\right)$ that considers as variables the density and isothermal compressibility of the solvent, as well as the second cross solvent-solute virial coefficient $\left(\beta_{12}\right)$ and the second virial coefficient of pure solvent $\left(\beta_{11}\right)$. The mathematical equation is applicable to solutes whose $\beta_{12}$ is known or can be estimated, in a temperature range of $273.16 \mathrm{~K}$ to $647 \mathrm{~K}$, values of pressure up to $2 \mathrm{kbar}$ and brines with ionic strength equal to $6 \mathrm{~m} \mathrm{NaCl}$. The expression provides excellent correlation with experimental data as shown for the $\mathrm{H}_{2} \mathrm{~S}-\mathrm{H}_{2} \mathrm{O}-\mathrm{NaCl}$ system (with maximum deviation of $7 \%$ ), through a thermodynamic model that uses this formula proposal coupled with the Law of Henry and the Soave- Redlich-Kwong equation of state for modeling the liquidvapor phase equilibria.
\end{abstract}

Keywords: Thermodynamic modeling, Poynting correction.

\section{INTRODUCTION}

The development of an equation for determining the isothermal pressure increment of the standard (infinite dilution) Gibbs free energy (or chemical potential) of a volatile solute on the basis of its partial molar volume at infinite dilution applicable to subcritical temperatures, based on parameters with available experimental data in the literature or easily estimated, as used in this work (the partial molar volume at infinite dilution of the volatile aqueous nonelectrolyte solute, the density and isothermal compressibility of solvent and the second virial coefficients) is of paramount importance in the field of modeling and interpretation of phase equilibrium thermodynamics in a wide range of temperatures and pressures /densities for practical applications in chemistry, physical chemistry, geochemistry and industrial technology [2-4]. In this paper we use the semitheoretical expression for the partial molar volume at infinite dilution for an aqueous non-electrolyte solute $\left(V_{2}^{0}\right)$ developed by Plyasunov et al. (2000a and b) based on the fluctuation solution theory [5] as well as in the fluctuation theory of statistical mechanics of a solution [6-8]. the equation contains the aforementioned density $(\rho)$ and the isothermal compressibility of solvent $(\kappa)$, as well as the second

*Address correspondence to this author at the National Autonomous University of México, México; Tel: (52) 4422737713 ;

E-mail: jmreyes@geociencias.unam.mx solvent-solute cross virial coefficient $\left(\beta_{12}\right)$ and the second virial coefficient of pure solvent $\left(\beta_{11}\right)$, so it can be used in a wide range of temperature and pressure. The equation used $[1,9]$ is the next:

$$
\begin{aligned}
& V_{2}^{0}=N V_{1}^{0}+\kappa_{P T} R T(1-N)+\ldots \\
& 2 \kappa_{P T} R T \rho_{P, T} \Omega\left(\beta_{12}-N \beta_{11}\right) e^{-C 1 \rho_{P, T}}+\ldots \\
& \left(\frac{a}{T^{5}}+b\right)\left(e^{C_{2} \rho P, T}-1\right)
\end{aligned}
$$

\section{ANALYTICAL INTEGRATION OF $V_{2}^{0}$}

To obtain the equation for determining the isothermal change of the standard (infinite dilution) Gibbs free energy (or chemical potential) of the volatile solute, is integrated analytically with respect to pressure the expression of the partial molar volume at infinite dilution of the volatile aqueous non-electrolyte solute according to the expression [9]:

$\Delta G_{2}^{0}=\int_{P_{s a t}}^{P} V_{2}^{0} d P$

To integrate the equation of the partial molar volume at infinite dilution for volatile aqueous nonelectrolyte solutes respect to the pressure, some auxiliary correlations were used [4, 10-12], finally obtaining the equation: 


$$
\begin{aligned}
& \int_{P_{s a t}}^{P} V_{2}^{\infty} d P=\int_{P_{s a t}}^{P}\left[\begin{array}{c}
N V_{1}^{0}+\kappa_{P T} R T(1-N)+\ldots \\
2 \kappa_{P, T} R T \rho_{P, T} \Omega \ldots \\
\left(\beta_{12}-N \beta_{11}\right) e^{-C_{1} \rho P, T} \\
+\left(\frac{a}{T^{5}}+b\right)\left(e^{C_{1} \rho P, T}-1\right)
\end{array}\right] d p \\
& \Delta G_{2}^{0} \int_{P_{\text {sat }}}^{P} V_{2}^{0} d p=\Delta G_{2}^{0}(A)+\Delta G_{2}^{0}(B)+\Delta G_{2}^{0}(C)+\Delta G_{2}^{0}(D) \\
& \Delta G_{2}^{0}(A)=\int_{P_{s a t}}^{P} N V_{1}^{0} d p=\frac{V v_{0}\left(P_{\text {sat }}+B\right)^{A}}{1-A} \ldots \\
& {\left[\frac{1}{(P+B)^{A-1}}-\frac{1}{\left(P_{\text {sat }}+B\right)^{A-1}}\right]} \\
& \Delta G_{2}^{0}(B)=\int_{P_{s a t}}^{P} \kappa_{P, T} R T(1-N) d p= \\
& R T(1-N) \operatorname{In}\left[\frac{P+B}{P_{s a t}+B}\right]^{A} \\
& \Delta G_{2}^{0}(C)=\int_{P_{s a t}}^{P} \begin{array}{c}
2 \kappa_{P, T} R T \rho_{P, T} \Omega \ldots \\
\left.-N \beta_{11}\right) e^{-C_{1} \rho P, T} d p
\end{array} \\
& \Delta G_{2}^{0}(C)=2 R T \Omega\left(\beta_{12}-N \beta_{11}\right) \ldots \\
& \left(\frac{1}{C_{1}}\right)\left\{\exp \left[-\frac{C_{1}}{v_{0}}\right]-\exp \left[-C_{1} \rho_{P, T}\right]\right\}
\end{aligned}
$$

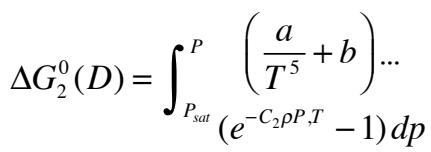

$$
\begin{aligned}
& \Delta G_{2}^{0}(D)=\left(\frac{a}{T^{5}}+b\right) \cdots \\
& \left\{\begin{array}{c}
\frac{C_{2}}{v_{0}\left(P_{\text {sat }}+B\right)^{A}}\left[\begin{array}{c}
(P+B)^{A+1} \\
-\left(P_{\text {sat }}+B\right)^{A+1}
\end{array}\right]+\ldots \\
\frac{C_{2}^{2}}{2 v_{0}^{2}\left(P_{\text {sat }}+B\right)^{2 A}(2 A+1)} \ldots \\
{\left[(P+B)^{2 A+1}-\left(P_{\text {sat }}+B\right)^{2 A+1}\right] \ldots} \\
+\frac{C_{2}^{3}}{6 v_{0}^{3}\left(P_{\text {sat }}+B\right)^{3 A}(3 A+1)} \ldots \\
{\left[(P+B)^{3 A+1}-\left(P_{\text {sat }}+B\right)^{3 A+1}\right] \ldots}
\end{array}\right\}
\end{aligned}
$$

EXAMPLE OF APPLICATION IN THE $\mathrm{H}_{2} \mathrm{~S}-\mathrm{H}_{2} \mathrm{O}-\mathrm{NACL}$ SYSTEM

This mathematical tool is applicable below the critical temperature of pure water $\left(674^{\circ} \mathrm{K}\right)$, pressures up to 2 Kbars and molalities equal to $6 \mathrm{~m}$ for $\mathrm{NaCl}$ solutions, in the field of modeling and interpretation of phase equilibrium thermodynamics, where the standard partial molar Gibbs energy of hydration for the nonelectrolyte solute is the most important thermodynamic property [9], because with this thermodynamic property is applied the Poynting correction in phase equilibrium thermodynamic modeling [13]. The equation is restricted to solutes for wich are known or can be estimated their $\beta_{12}$ (second virial cross solvent-solute coefficient). The expression provides excellent correlation with experimental data [14] as shown for the $\mathrm{H}_{2} \mathrm{~S}-\mathrm{H}_{2} \mathrm{O}-\mathrm{NaCl}$ system, using a thermodynamic model $[3,4]$ that uses this mathematical tool developed coupled with the Henry's Law and the Soave-RedlichKwong equation of state [14] to reproduce experimental data in the aqueous liquid and vapor region [3, 4], as can be observed in the following Figure 1:

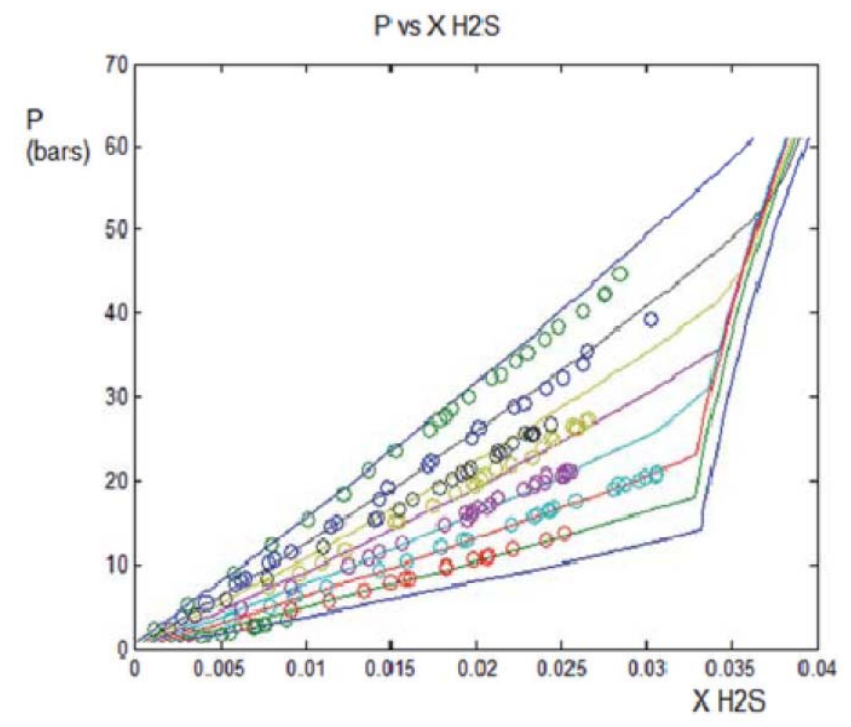

Figure 1: The solid line is the calculation of the thermodynamic model with analytical integration for $V_{2}^{0}$ and the symbols are the experimental data by Lee and Mather (1977) [14].

\section{CONCLUSIONS}

In this work we developed a mathematical expression for the isothermal pressure increment of the standard (infinite dilution) Gibbs free energy (or chemical potential) of the volatile non-electrolyte solute, applicable below the critical temperature of pure water $\left(674^{\circ} \mathrm{K}\right)$, pressures up to $2 \mathrm{Kbars}$ and molalities equal to $6 \mathrm{~m}$ for $\mathrm{NaCl}$, analytically integrating respect to the pressure the semitheoretical expression for the partial molar volume at infinite dilution for an aqueous nonelectrolyte volatile solute, applicable for the Poynting correction in thermodynamic modeling. The 
mathematical expression developed provides excellent correlation with experimental data.

\section{REFERENCES}

[1] Martínez RJ, Pérez RJ, González PE. y Tinoco M JA. Ecuación Para la Corrección Poynting en Termodinámica de Equilibrio de Fases Gases No Polares-Sistemas Acuosos. Aplicación al Sistema $\mathrm{H}_{2} \mathrm{~S}-\mathrm{H}_{2} \mathrm{O}-\mathrm{NaCl}$ Boletín de la Sociedad Geológica Mexicana 2010; 62(2): 213-20.

[2] Plyasunov A, O'Connel J, Wood R. Infinite dilution partial molar properties of aqueous solutions of nonelectrolytes. I. Equations for partial molar volumes at infinite dilution and standard thermodynamic functions of hydration of volatile nonelectrolytes over wide ranges of conditions: Geochimica et Cosmochimica Acta 2000a; 64: 495-12. http://dx.doi.org/10.1016/S0016-7037(99)00322-1

[3] Perez RJ, Heidemann RA. Coupling an equation of state and henry's law to model the phase equilibria of gases and brines examples in the $\mathrm{N}_{2}-\mathrm{H}_{2} \mathrm{O}-\mathrm{NaCl}$ system. J Geochem Explorat 2006; 89: 331-34. http://dx.doi.org/10.1016/j.gexplo.2005.11.083

[4] Pérez RJ, Heidemann RA, y González-Partida E. Modelo teórico para el cálculo de las solubilidades mutuas entre gases no-polares y agua con sales disueltas. Boletín de la Sociedad Geológica Mexicana 2009; 61(3): 325-37.

[5] Kirkwood JG, Buff FP. The statistical mechanical theory of solutions. I J Chem Phys 1951; 19: 774-82. http://dx.doi.org/10.1063/1.1748352

[6] O'Connell JP. Thermodynamic properties of solutions based on correlation functions. Mol Phys 1971; 20: 27-29. http://dx.doi.org/10.1080/00268977100100031

[7] O'Connell JP. Thermodynamics and fluctuation solution theory with some applications to systems at near- or supercritical conditions. In Supercritical Fluids: Fundamentals for Application. Kiran E, Levelt Sengers JMH, Eds. NATO ASI Series Applied Sciences 1994; Vol. 273: pp. 191-229.

[8] O'Connell JP. Application of fluctuation solution theory to thermodynamic properties of solutions. Fluid Phase Equilibria 1995; 104: 21-39.

http://dx.doi.org/10.1016/0378-3812(94)02637-G

[9] Plyasunov A, O'Connel J, Wood R, Shock E. Infinite dilution partial molar properties of aqueous solutions of nonelectrolytes. II. equations for thestandard thermodynamic functions of hydration of volatile nonelectrolytes over wide ranges of conditions including subcritical temperatures. Geochimica et Cosmochimica Acta 2000b; 64(16): 2779-95. http://dx.doi.org/10.1016/S0016-7037(00)00390-2

[10] Rowlinson J, Swinton F. Liquids and liquid mixtures: Butterwoths Monographs in Chemistry: London, Butherworth Scientific 1982; p. 328

[11] Heidemann R, Jeje A, Mohtadi F. An introduction to the properties of fluids and solids, Calgary. University of Calgary Press 1987; p. 401.

[12] Kell G. Density, Thermal Expansivity, and Compressibility of liquid water from 0 to $150 \mathrm{C}$; Correlations 1975.

[13] Fernandez-Prini R, Alvarez JL, Harvey AH. Henry's constants and vapor-liquid distribution constants for gaseous solutes in $\mathrm{H}_{2} \mathrm{O}$ and $\mathrm{D}_{2} \mathrm{O}$ at high temperatures. J Phys Chem 2003; 32(2).

[14] Lee JI, Mather AE. Solubility of hydrogen sulfide in water Ber Bunsenges Phys Chem 1977; 81: 1021-23. http://dx.doi.org/10.1002/bbpc.19770811029

[15] Soave G. Equilibrium constants from a modified RedlichKwong equation of state. Chem Eng Sci 1972; 27(6): 1197203. http://dx.doi.org/10.1016/0009-2509(72)80096-4 